$$
\begin{aligned}
& \text { زينب قائدى، ريحانه صابرى پييروز، الهام ابراهيمى، سحر بدرى و فراهم احمدزادئ }
\end{aligned}
$$

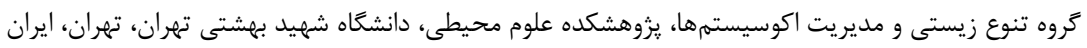

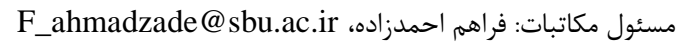

جكيده. روشهاى متفاوتى براى بررسى تاثيرات نوسانات اقليم بر روى موجودات وجود دارد. از ميان آنها جغرافياى تبارشناختى (Phylogeography) و

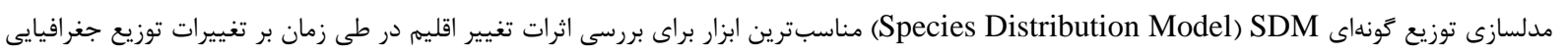

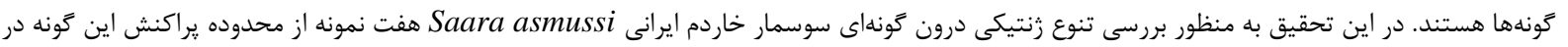

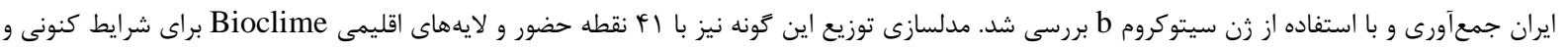

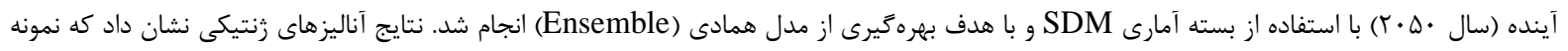

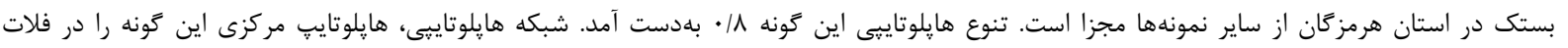

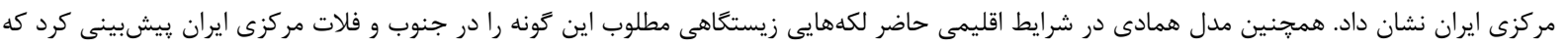

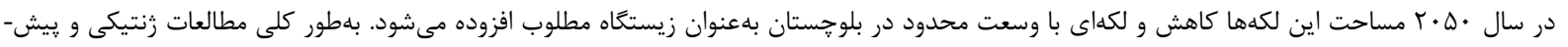

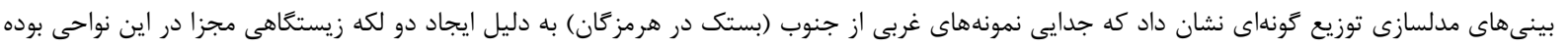

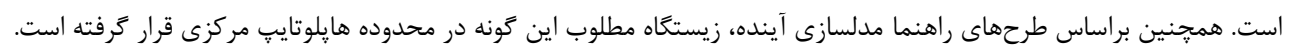

$$
\text { وازههاى كليدى. زن ميتوكندريايى، سوسمار خاردم، فلات ايران، مدل همادى، مدل سازى توزيع كَونهاى }
$$

\title{
Genetic diversity within the Iranian spiny-tailed lizards and predicting species distribution in climate change conditions
}

\author{
Zeinab Ghaedi, Reihaneh Saberi-Pirooz, Elham Ebrahimi, Sahar Badri \& Faraham Ahmadzadeh \\ Department of Biodiversity and Ecosystem Management, Environmental Sciences Research Institute, Shahid Beheshti \\ University, G.C., Evin, Tehran, Iran \\ Correspondent author: Faraham Ahmadzadeh, F_ahmadzade@ sbu.ac.ir
}

\begin{abstract}
There are different methods to investigate the effects of climatic fluctuations on the biota, two of which, molecular phylogeography and SDM, are the most useful tools to trace the past climate induced modifications on species' geographic distributions. In this study, seven samples were collected from the species distribution range in Iran for the purpose of measuring the genetic variation within the Iranian spiny-tailed lizards, using cytochrome b. SDM was carried out by 41 presence points and bioclimatic variables for the present and future climatic conditions (by the year 2050), employing the statistical package 'sdm' in order to implement the ensemble model. The results of genetic analyses revealed that the specimens from Bastak in Hormozgan Province are distinguishable from all other specimens. Haplotype diversity was calculated as 0.8 . The haplotype network illustrated that the central haplotype is located in the central Iranian Plateau. Moreover, the ensemble model predicted that, while the suitable habitats of this species were found to be in the south of Iran and the Iranian Central Plateau in the present climatic conditions, there will be a decrease in the extent of these patches and Baluchistan will be added as a suitable habitat in 2050. Generally, both genetic studies and modeling predictions suggested that the western and southern specimens (Bastak in Hormozgan) were divided according to the separation of their habitats. In addition, based on modeling scenarios in the future, the optimal habitat for the species is located in the central haplotype area.
\end{abstract}

Keywords. Ensemble model, Iranian plateau, mitochondrial gene, species distribution model, spiny-tailed lizard 
تعداد زياد آرايههايى كه امروزه زندكى مى كنند ضرورى است بلكه حفظ سطح بالايى از تنوع زيستى در آينده مورد نياز است.

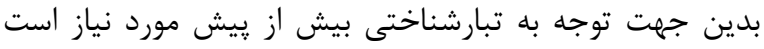

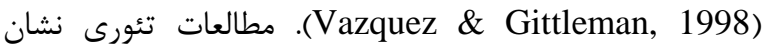
دادند كه بالا بودن تنوع تبارشناختى در جامعه، پتانسيل تكاملى

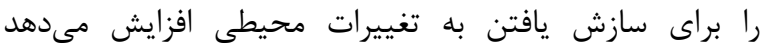
Mouquet et al., 2012; Sgro et al., 2011; Meynard et ) al., 2011; Bellwood et al., 2003 زنتيكى به عنوان يك شاخصى براى بحران تنوع زيستى ارائه

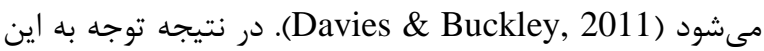
كونه، مطالعه گسترده در زمينه تنوع زنتيكى و زيستخاه آن حائز

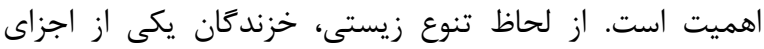

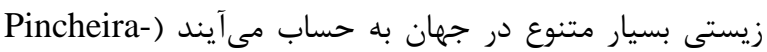
(Donoso et al., 2013 سوسمارها يكى از ساكنان بسيار گسترده در دنياى قديم به شمار مىروند (Ananjeva et al., 2006). سوسمارهاى خاردمان يكى از زيرخانوادههاى آكاميده بوده كه (Uromasticinae) داراى رنغَهاى متنوع و اندازهى متوسط تا بزرى هستند

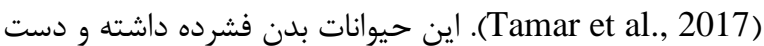

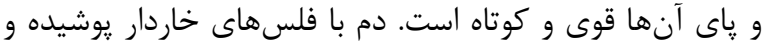

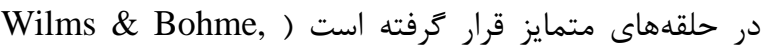
2007). سوسمارهاى خاردم داراى ريخت شناسى و و اسكلت خاص و ساختمان دندانى آكرودنت هستند كه دندانها در بالغين جايكزين نمىشود (Porro et al., 2014). اعضاى اين زيرخانواده ساكن مناطق صاحارا-سندى هستند و در كمربند

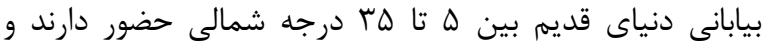

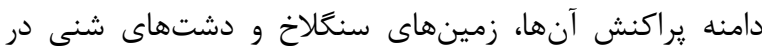

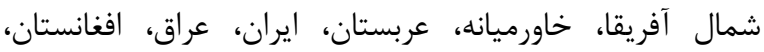

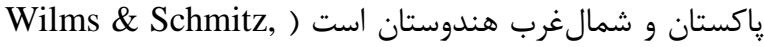
2007). با وجود اينكه زيستگاه اين سوسمارها در بيشتر مواقدانع بصورت مستقيم در معرض تهديد قرار نمى كيرد و بيشتر شامل بيابانهاى بدون كاربرى است و در مكانهايى دور از محل

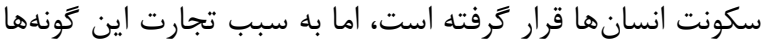

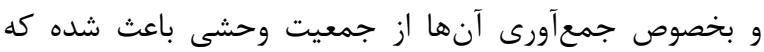

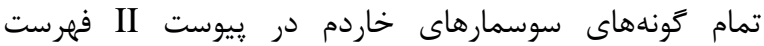

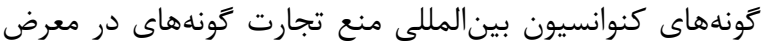
خطر Convention on International Trade in ) CITES (Endangered Species اطلاعات ريخت شناسى و مولكولى بر اساس زن ميتوكندريايى

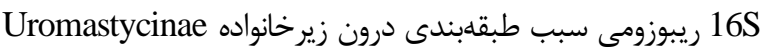

مقاله به طور كلى تنوع زيستى شامل تنوع حيات در روى زمين است (Gaston \& Spicer, 2004). اقليم به عنوان متوسط شرايط آب و هوايى در يك منطقه خاص و معين توصيف مى

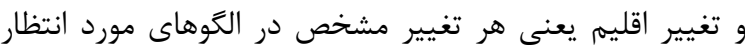

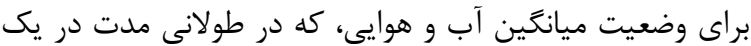

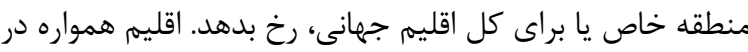

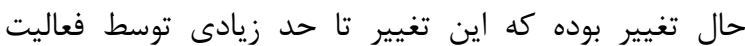
خورشيد و كردش جو صورت مىيذيرد، اما تغيير اقليم اخير حداقل تا حدى ناشى از فعاليتهاى بشر بهواسطه افزايش غلظت كازهاى كلخانهاى است (Trisurat et al., 2011). روشهاى نائ متعددى براى بررسى اثرات تغييرات اقليمى بر روى توزيع گونهها

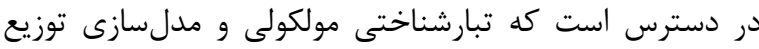
كونهاى Species Distribution Model) SDM از مهمترين اين روشها شناخته شدهاند (Ahmadzadeh et al., 2013). از آن جهت كه براى بيشبينى پاسخ گَونهها به تغييرات اقليم، نياز به به دانش بيشترى از نحوه توزيع گَونهها وجود دارد (

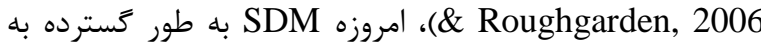
عنوان ابزار جديدى براى حفاظت، بررسى موضوعات اكولوزيكى و

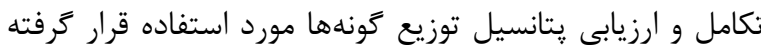

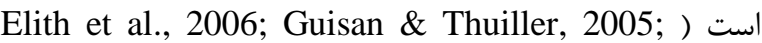
دeschke \& Strayer, 2008

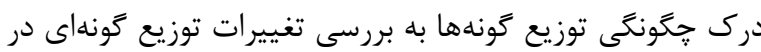

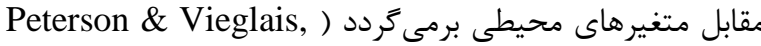
2001; Gaston, 2003; Huntley et al., 2004; Parmesan اين امكان را فراهم مى آورد تا بتوان SDM و (et al., 2005 مجموعهاى از فاكتورهاى محيطى اثركذار بر الخَىى توزيع كَنهاى

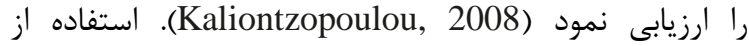
الكوريتهماى مختلف مدلسازى توزيع گونهاى تحت طرحهاى

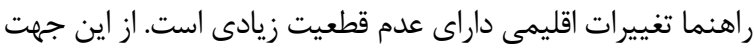
كه الكوريتمهاى مختلف كه در شرايط اقليمى كنونى دقت بالا و ودائ

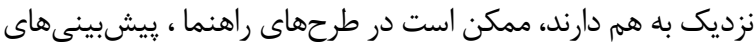

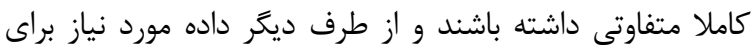
ارزيابى دقت مدلها در آينده وجود ندارد (Araújo et al., 2005)

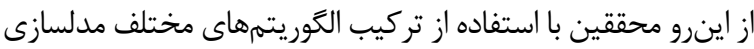

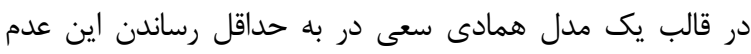
قطعيت داشتهاند (Ebrahimi, 2018). حفاظت از تنوع زيستى به منظور نكهدارى، حفظ، استفاده "ايايدار و بهبود بخشيدن عناصر تنوع زيستى است ( 2009). براى حفاظت از تنوع زيستى نه تنها در نظر كرفتن استى 
كونهاى سوسمار خاردم ايرانى و استفاده از مدلهاى توزيع كَونه S. asmussi

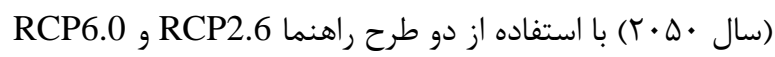
است.

\section{مواد و روش هات}

مطالعات زنتيكى درون كونهى سوسمار خاردم ايرانى

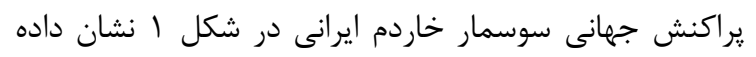

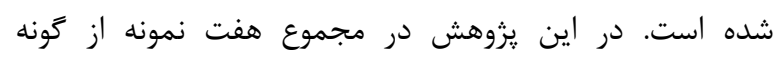

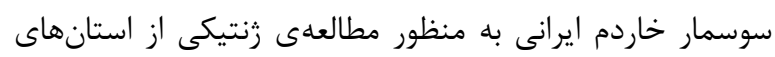

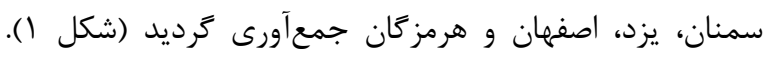

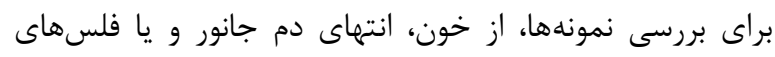

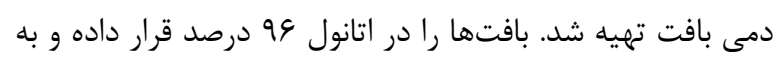
آزمايشَاه اكولوزى مولكولى يزوهشكده علوم محيطى دافئ دانشَاه

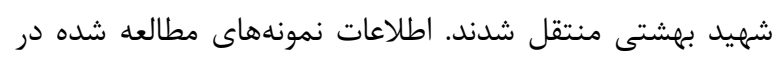

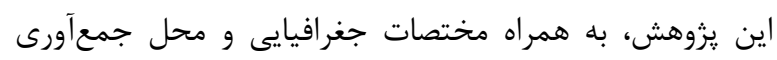

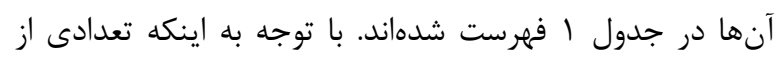

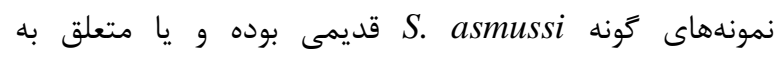

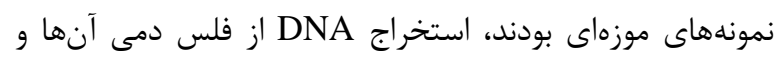

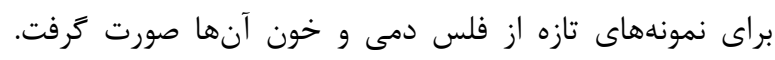

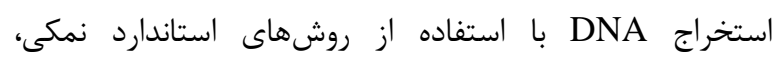

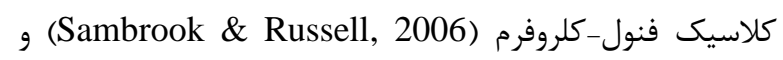

كيت استخراج Qiagen انجام شد.

واكنش زنجيرهاى يليمراز (PCR)

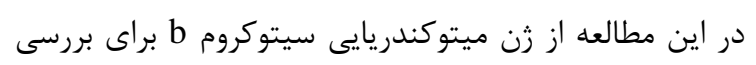

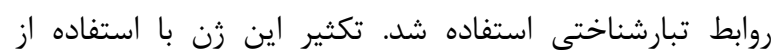

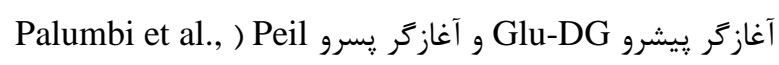

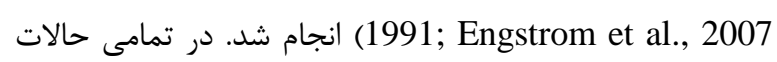

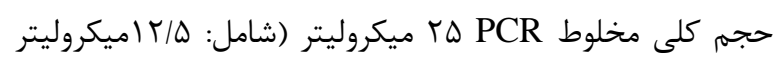

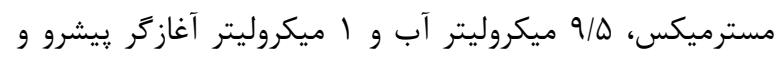

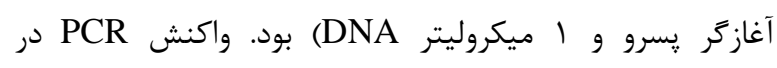

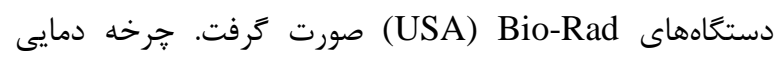

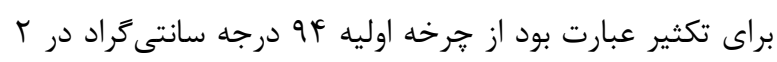

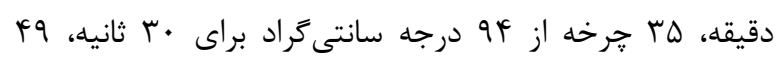
درجه سانتى

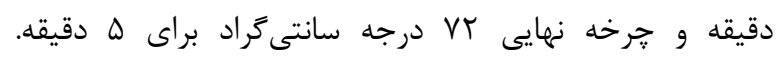

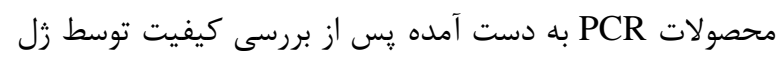

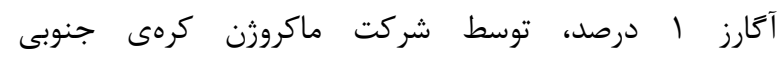
توالى يابى شدند.
شد. از اين رو به كلادى كه شامل كروه سوسمارهاى ناحيه ايران-

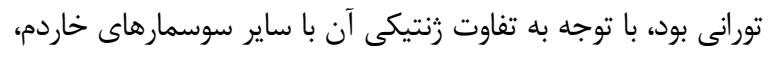

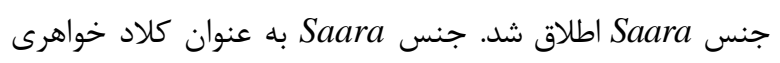

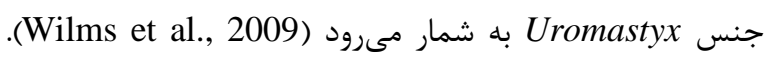
ييش از اين تصور بر آن بود كه تنها جنس Uromastyx

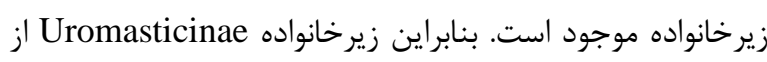

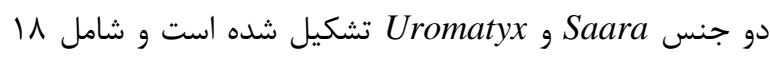
كونه است كه از اين ميان سه كونه Saara hardwickii Saara Saara loricata, Sara asmussi است. S. hardwickii إيايةترين موقعيت تبارشناختى

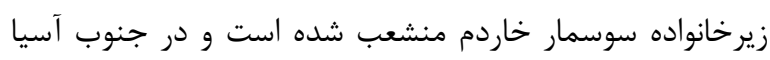

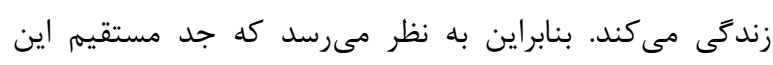

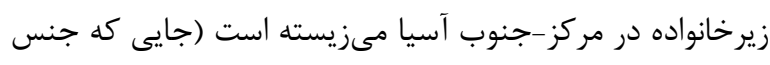
Uromastyx

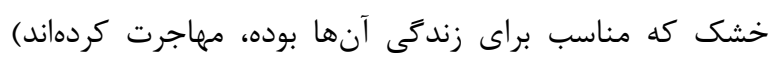
(Amer \& Kumazawa, 2005) شواهد ايمنولوزى مشخص شد كه هر دو تروه S. S. asmussi loricata كروه طبيعى را تشكيل ميدهند (Joger, 1986). اما بعدها

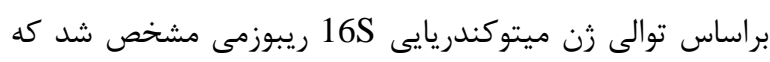
S. hardwickii با كو كونهى S. loricata asmussi S. تشكيل كلاد خواهرى مى Silms et al., 2009) asmussi

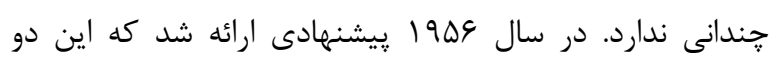

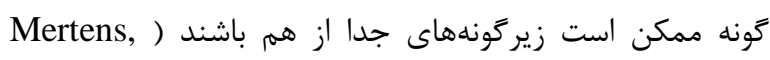

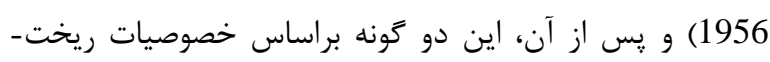

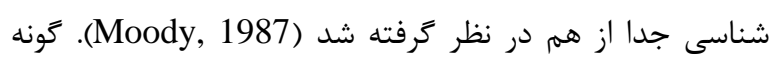

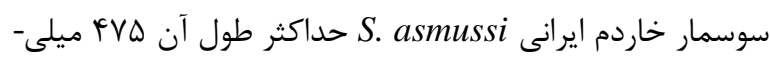

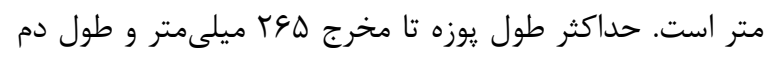

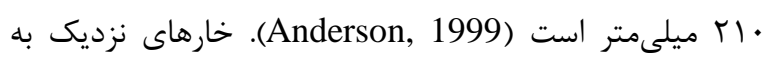

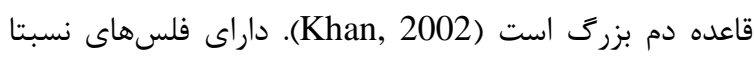

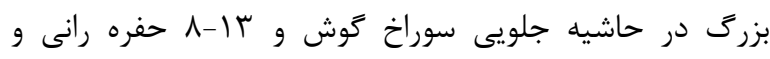

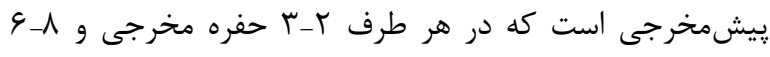

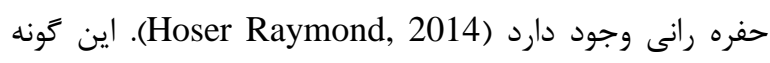

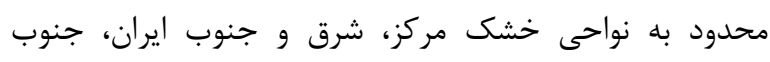

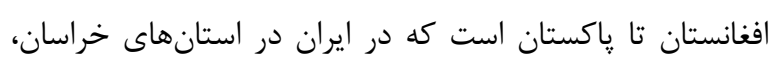

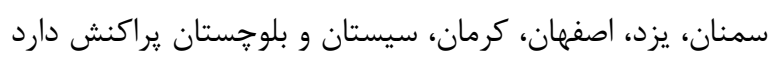
(Anderson, 1974) تاكنون مطالعات اندكى روى كونه S. asmussi انجام شده است. هدف از انجام اين تحقيق، بررسى تنوع رنتيكى دونى درون 
راهنما آينده شامل RCP2.6 و RCP6.0 است كه به ترتيب نماينده طرح راهنما خوشبينانه و بدبينانه در روند تغيير اقليم

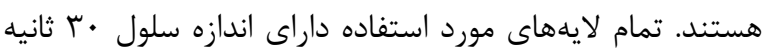

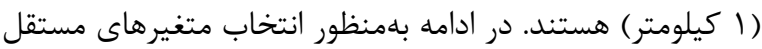

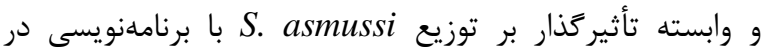

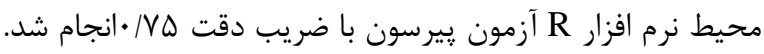

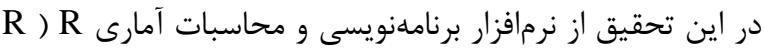

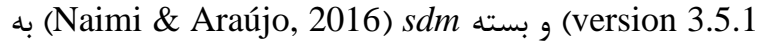
عنوان ابزار مدلسازى استفاده شد. اين بسته شامل: مدل خطى تعميم يافته (Generalized Linear Models)، مدل افزايشى مدارئ

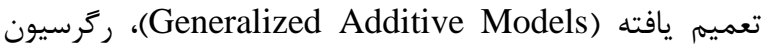

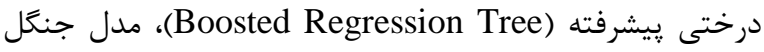

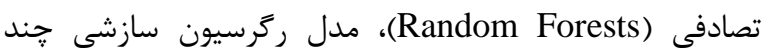

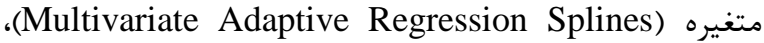

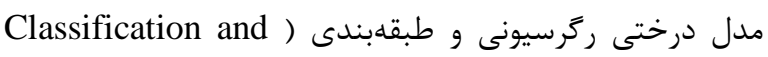
Regression Trees و و در نهايت مدل (Flexible Discriminant Analysis) همادى (Ensemble) به عنوان يك مدل تركيب ييشبينى هاى

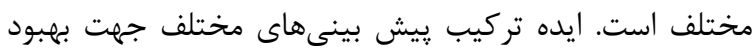
دقت و كاهش عدم قطعيت مدلهاى منفرد از ديرباز مورد توجه

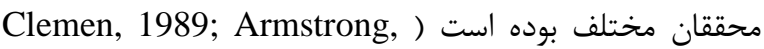
2001) كه به يُشبينى Ensemble معروف است. اين رويكرد

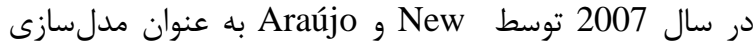
توزيع كونهاى معرفى كرديد (Araújo \& New, 2007). در كام

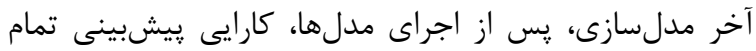

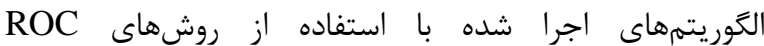
True ) TSS g (Receiver-Operating Characteristic) (Skill Statistic روشى كه منعكس كننده يديده اكولوزيكى واقعى به جاى يك إنى

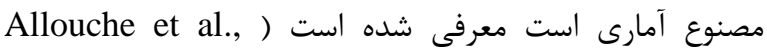

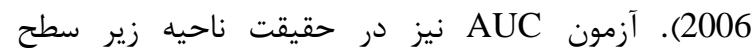

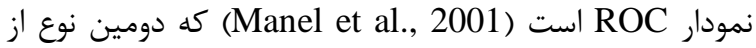

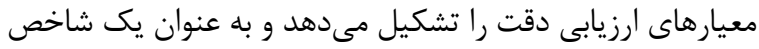

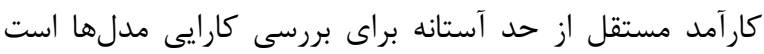

(Miller, 2010)

\section{نتايج}

مطالعات زنتيكى درون كونهى سوسمار خاردم ايرانى إنى

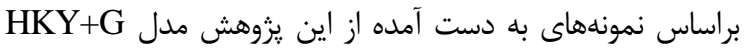

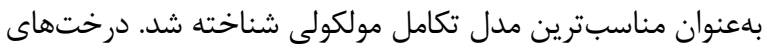

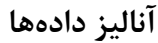

Codon code در اين تحقيق ابتدا توالىها با كمك نرم افزار

Codon Code Corporation, Dedham, ) aligner v.6.0.2

MEGA ويرايش كرديد و در ادامه از نرم افزارهاى (MA, USA

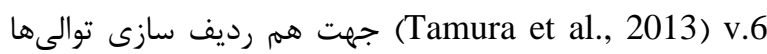
استفاده شد. سيس توالىها به صورت دستى كنترل شدند.

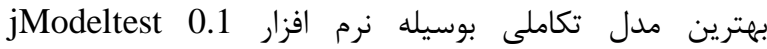
(Posada, 2008) RaxML با استفاده از نرم افزار (Maximum Likelihood) S.7.2 ) و با Stamatakis, 2006) (1... Bootstrap

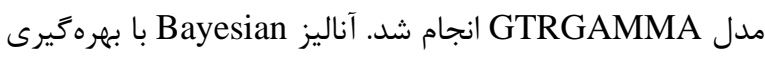

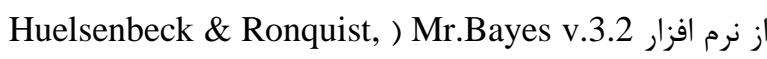

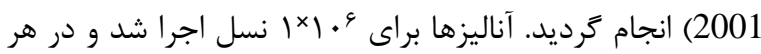

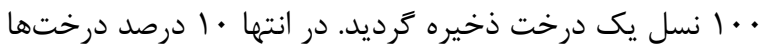
حذف شدند (Burn in). كونه Sardwikii) خارجى (Outgroup) در ترسيم درخت مورد استفاده قرار كرفت. جهت ترسيم شبكه هإِلوتاييى يارسيمونى ازنرم افزار

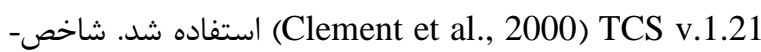
هاى تنوع شامل تعداد هإيلوتايب (H)، تنوع هايلوتايبى (Hd)،

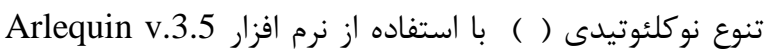
(Excoffier \& Lischer, 2010) مدلسازى توزيع سوسمار خاردم ايرانى در شرايط تغيير اقليم

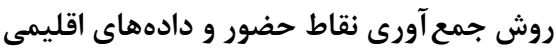

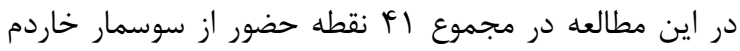

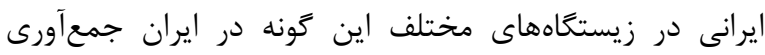

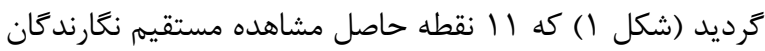

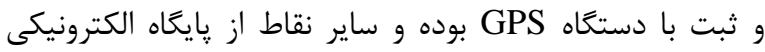

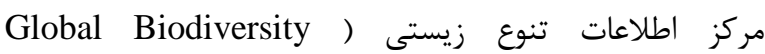
(www.GBIF.org) (Information Facility و مقالات منتشر شده خارجى مقال داخلى (Akbari et al., 2011; 2014) (Anderson, 1999; Wilms et al., 2009) اطلاعات جهانى در مقياسهاى مكانى مختلف (30 ثانيه تا 10

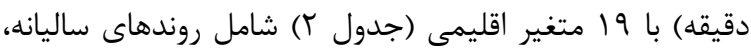

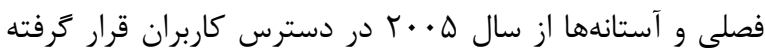

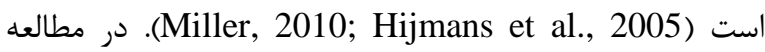

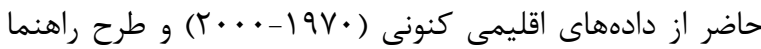
(Representative Concentration Pathways) RCP

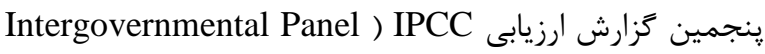
(on Climate Change استفاده شده است. طرحهاى (http://www.worldclim.org) 
(A)

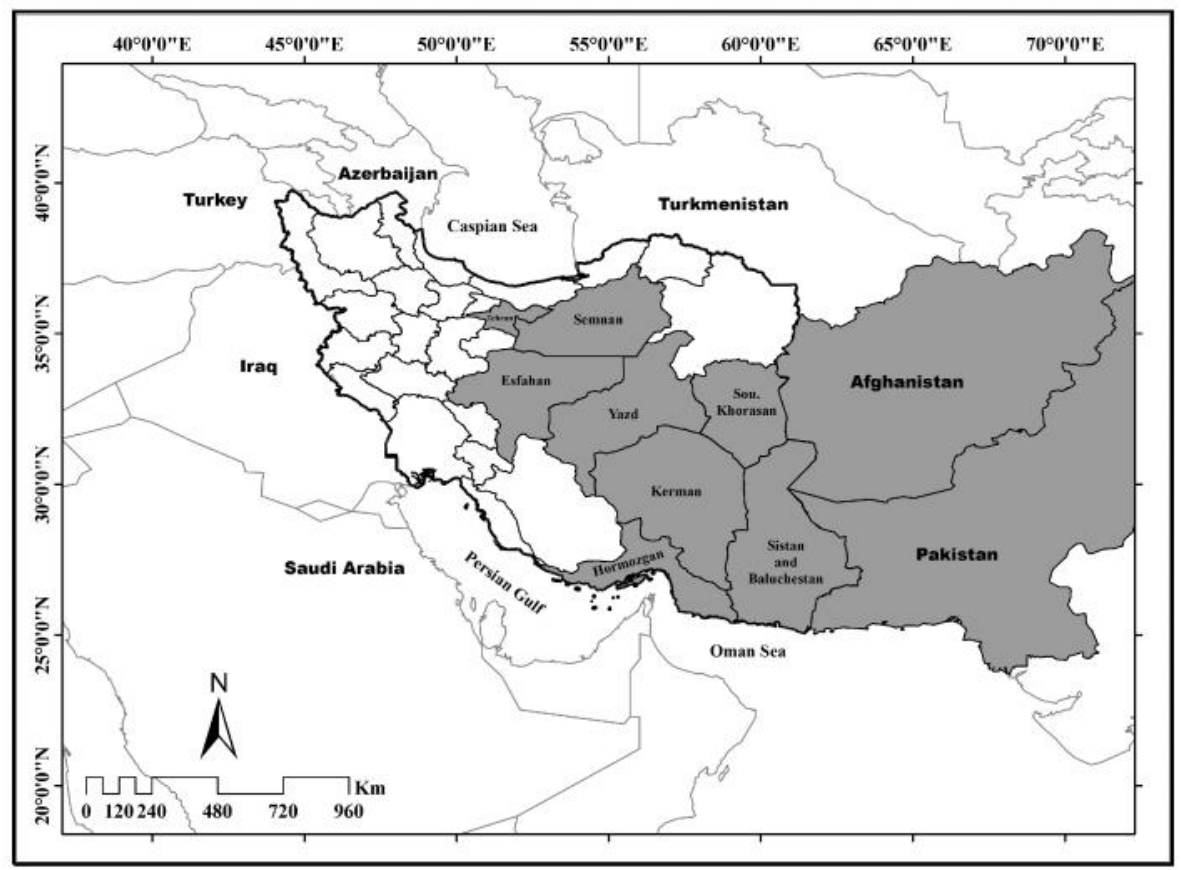

(B)

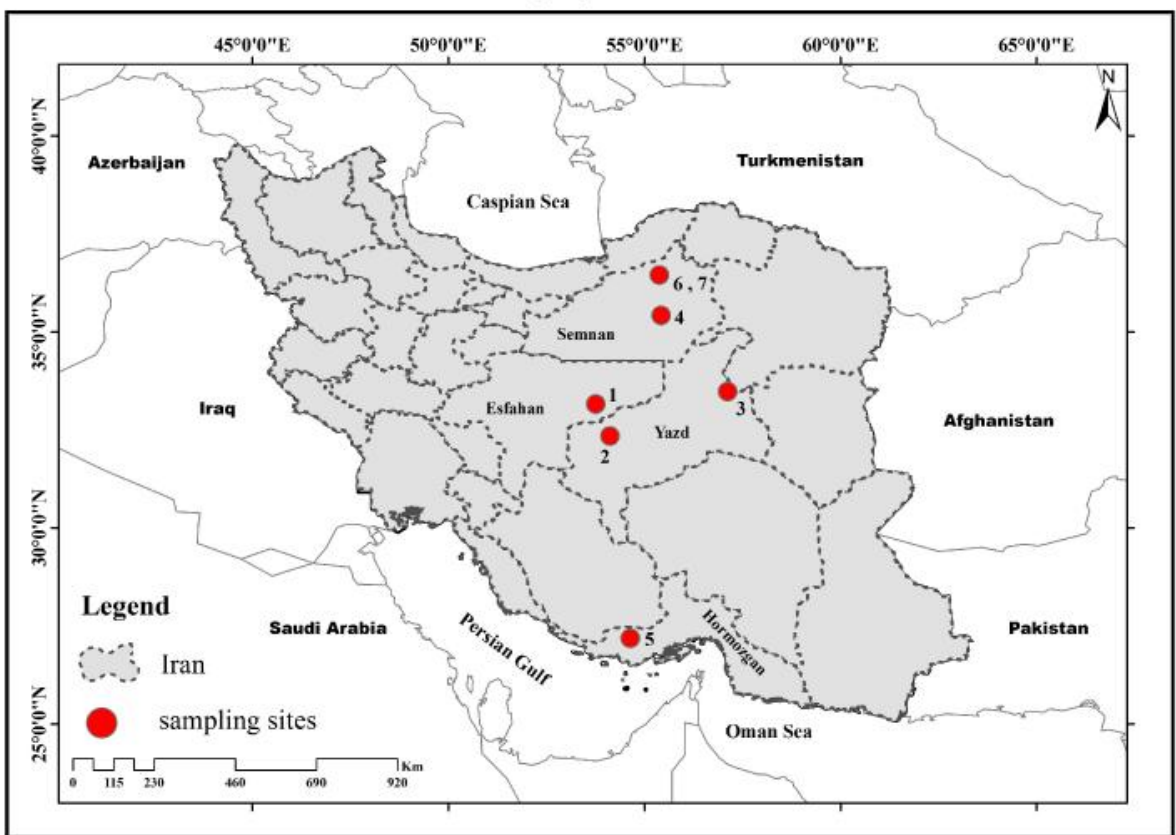

شكل ا- نقشه يراكنش و نمونهبردارى A Saara asmussi. نقشه يراكنش جهانى B. Saara asmussi. نقشه ايستعاههاى نمونه بردارى Saara asmussi

Fig. 1. Map of distribution and sampling for Saara asmussi. A. Global distribution map for Saara asmussi. B. Map of sampling sites of Saara asmussi in Iran (1-Naeen, 2-Ardakan, 3-Moaazam Abad Village, 4-Torud, 5-Bastak, 6,7Shahrud). 
جدول ا- جدول مشخصات نمونهاى مورد مطالعه در اين يزوهش شامل كد نمونه، محل جمعآورى و مختصات جغرافيايى.

Table 1. List of samples used for genetic analyses in this study, including codes, localities and geographical coordinates.

\begin{tabular}{|c|c|c|c|c|}
\hline \multicolumn{2}{|c|}{ مختصات جغرافيايى } & \multicolumn{2}{|c|}{ محل جمع آورى } & \multirow{2}{*}{ كدنمونه } \\
\hline طول جغرافيايى & عرض جغرافيايى & استان & شهرستان & \\
\hline 53.86 & 33.18 & اصفهان & نايين & Saas01 \\
\hline 54.00 & 32.31 & 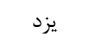 & اردكان & Saas02 \\
\hline 56.92 & 33.61 & يزد & روستاى معظم آباد & Saas 03 \\
\hline 55.10 & 35.42 & سمنان & طرود ل & Saas04 \\
\hline 54.37 & 27.20 & هرمز كان & بستك & Saas 05 \\
\hline 55.11 & 36.41 & سمنان & شاهرود & Saas06 \\
\hline 55.11 & 36.41 & سمنان & شاهرود & Saas07 \\
\hline
\end{tabular}

جدول r- متغيرهاى اقليمى مورد استفاده براى تهيه مدل توزيع گَنهاى سوسمار خاردم ايرانى.

Table 2. The applied bioclimatic variables to create the distribution model of Iranian spiny-tailed lizards.

\begin{tabular}{|c|c|c|c|}
\hline عنوان & متغير & عنوان & متغير \\
\hline دماى متوسط سردتر ين فصل & BIO11 & دماى متوسط سالانه & BIO1 \\
\hline بارند كى سالانه & $\mathrm{BIO} 12$ & ميانكَين دماى روزانه & BIO2 \\
\hline بارش مرطوبترين ماه سال & BIO13 & ميانكَين دماى مطلق هوا & BIO3 \\
\hline بارش خشكترين ماه سال & BIO14 & دماى فصلى & BIO4 \\
\hline بارش فصلى & BIO15 & حداكثر درجه حرارت كَرمترين ماه سال & BIO5 \\
\hline بارش در مرطوبترين فصل & BIO16 & حداقل دما در سردترين ماه سال & BIO6 \\
\hline بارش در خشكترين فصل & BIO17 & محدوده دماى سالانه & BIO7 \\
\hline بارش در كرمترين فصل & BIO18 & متوسط دماى فصل مرطوب & BIO8 \\
\hline \multirow[t]{2}{*}{ بارش در سردترين فصل } & BIO19 & متوسط دماى فصل خشك & BIO9 \\
\hline & & متوسط دماى كرمترين فصل & BIO10 \\
\hline
\end{tabular}

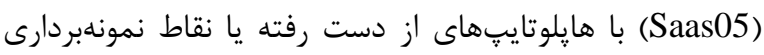

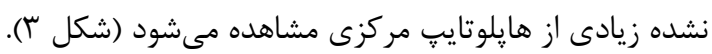

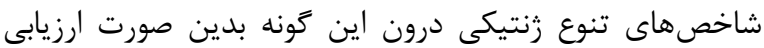
شد:

ييشبينى توزيع سوسمار خاردم ايرانى در شرايط تغيير اقليم

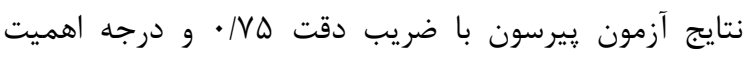

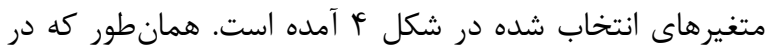

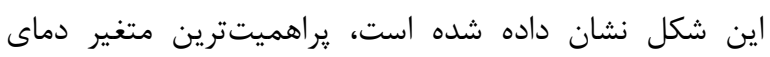
متوسط سردترين فصل سال است. ميانگين عملكرد هر مدل مطابق شكل ه ارزيابى شده است. شاخص AUC وضعيت بهترى

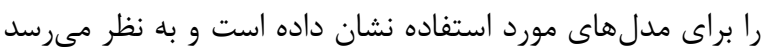
شاخص TSS شاخص سختخيرانهترى در صحت سنجى مدلها بهخصوص براى مدل RF در شرايط حاضر است. همجنين در مجموع با توجه به هر دو شاخص صحتسنجى به نظر مىرسد مدل GLM داراى اعتبار به مراتب بيشترى نسبت به ساير مدلهاى مورد استفاده در تجزيه و تحليلها است. كمترين ميزان
به دست آمده براى V نمونه با طول توالى 9 ه جفت باز رسم

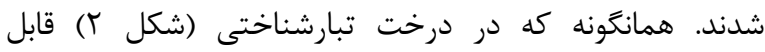
مشاهده است نمونه بستك هرمزگًان (Saas05) از ديخر نمونهها مجزا شده و نمونههاى طرود در سمنان، اردكان و طبس در يزد و و

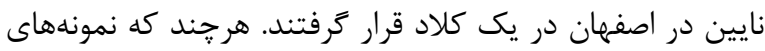
شاهرود (Saas06 وSaas07) نيز در كلاد اصلى اندكى لهى ازساير

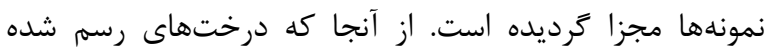

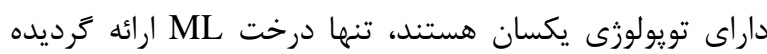

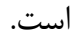
همانطور كه نتايج شبكه هايلوتاييى نشان مىدهد كونه

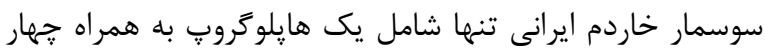
هايلوتايتٍ است. هايلوتايتٍ مركزى شامل سه فرد ( Saas01,

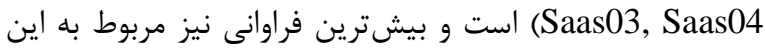
هايلوتايب است. هايلوتايٍ دو و جهار به ترتيب شامل يك فرد (Saas02) و دو فرد (Saas06, Saas07) بوده است. نمونه 
مطالعه روابط تبارشناختى كونههاى مختلف موجود در فلات

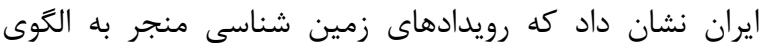

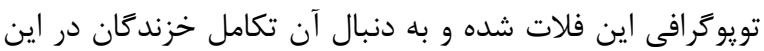

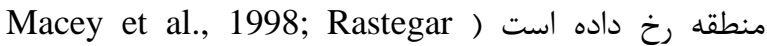

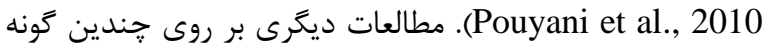
از خزندًان فلات ايران (مولكولى و ريخت شناسى) صورت كرفته

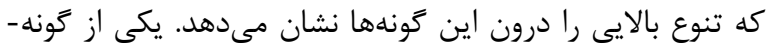
هاى مطالعه شده در اين ناحيه كونه است كه توزيع جغرافيايى گستردهاى در فلات آناته ايران داشته است. براساس مطالعات مختلف براى اين كونه جند واحد تاكسونوميك مختلف تشخيص داده شد ) Gray, 1845;

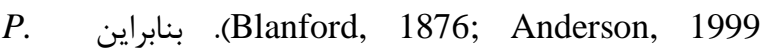
scutellatus آناليزهاى مولكولى در كونه كميلكس P. scutellatus در ايران

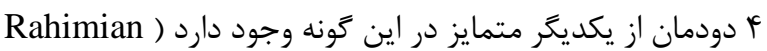

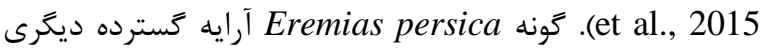
در فلات ايران است كه بدليل زندكى در زيستگًاههاى متنوع در

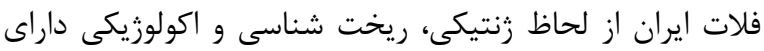
تنوع است ) Szczerbak, 1974, 2003; Arnold, 1986; .(Anderson, 1999; Rastegar Pouyani et al., 2010 اطلاعات ريختشناسى و زنتيكى نشان داد كه اين كونه

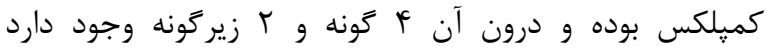
Rastegar Pouyani et al., 2010)

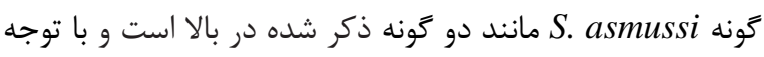
به تنوع بالاى زمينشناسى فلات ايران و گستردگى يراكنش اين

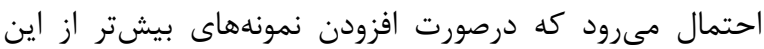
كونه تنوع بيشترى از اين كونه به دست آيد دورد آيد.

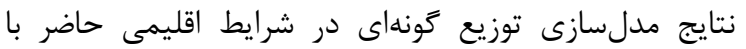
عمليات ميدانى نويسندكان اين مقاله در زيستخاههاى اين كونه

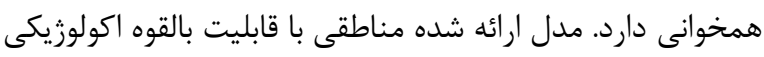

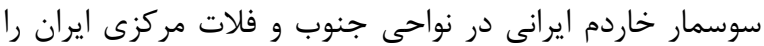

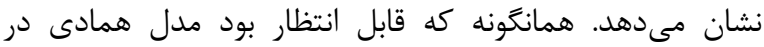

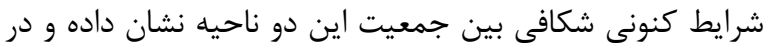

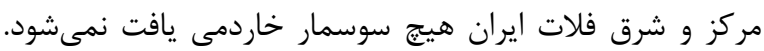

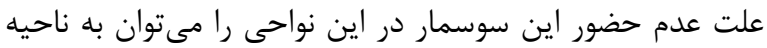

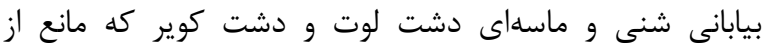

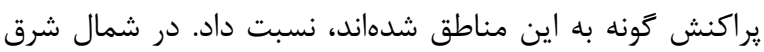
فلات ايران، دشت كوير به ناحيه سيستان و هلمند در كرانه شرق ايران و افغانستان متصل مىشود و يكى مانع ارتفاعى كوتاه به وجود

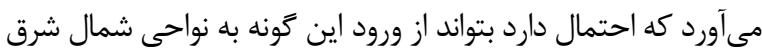

عددى صحتسنجى توسط شاخص TSS براى مدل RF و بيش-

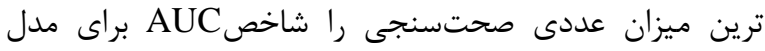

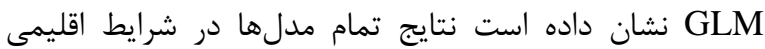
حاضر (شكل 9) نشان مىدهد بلمطور عمده بخشهايى از استان-

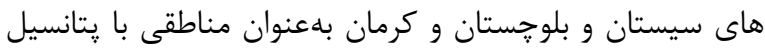

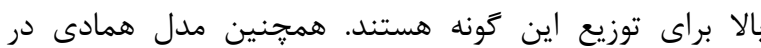

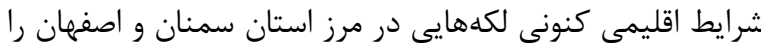
نيز بهعنوان مناطقى با مطلوبيت بالا مشخص كرده است. مطابق

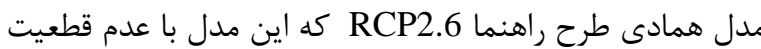
به مراتب كمترى از ساير مدلهاى منفرد به بِيشبينى توزيع

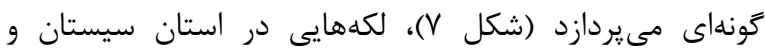

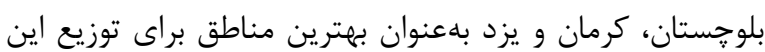

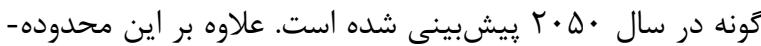

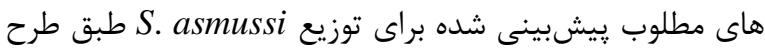

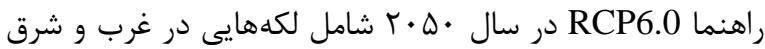

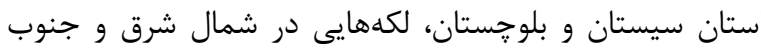

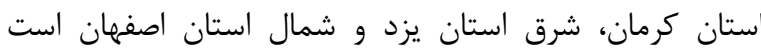

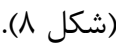

بحث

در اين مطالعه سعى شد تا گونه سوسمار خاردم ايرانى از نظر

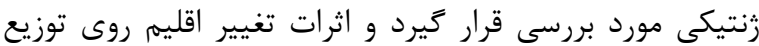

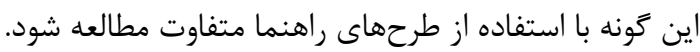

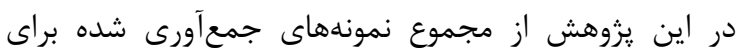
سوسمار خاردم ايرانى، نمونههايى كه در بخش مركزى براكنش

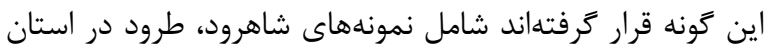
سمنان، اردكان و طبس در استان يزد و نايين در استان اصفهان

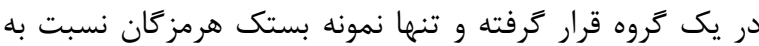

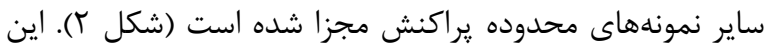
تفاوت مى تواند بدين جهت باشد كه نمونه بستك (هرمزكان) از لحاظ جغرافيايى فاصله زيادى از ساير نمونههاى مورد مطالعه

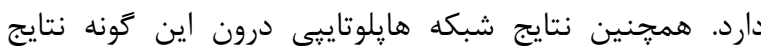
درخت بهدست آمده را مورد تاييد قرار مى دهد. با توجه به ائه اينكه هايلوتايٍ مركزى سوسمارخاردم ايرانى مربوط به بخش مركز

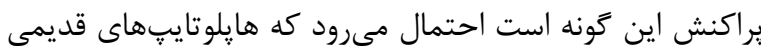
اين كونه مربوط به اين مناطق بوده و سيس كسترش ين يافته است. با توجه به اينكه اين مطالعه تنها براساس تعداد محدودى نمونه (هفت نمونه) انجام شده است، بنابراين اين احتمال وجود دارد

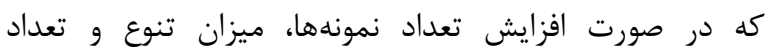
هايلوتايڤها افزايش يابد. 


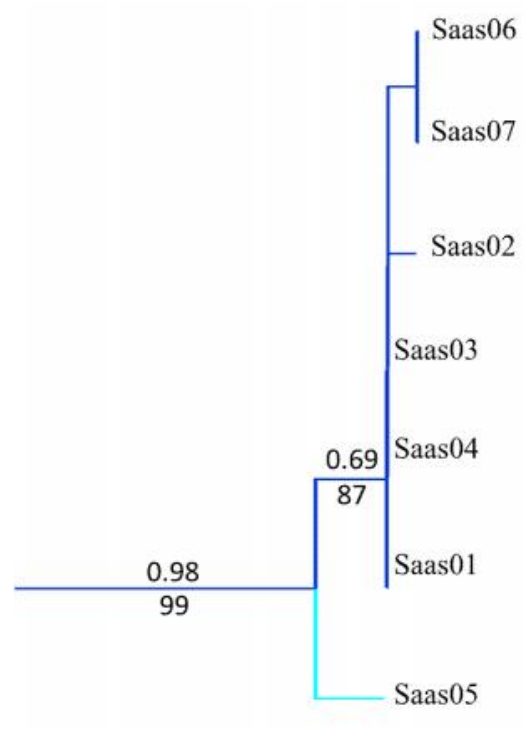

شكل r- درخت تبارشناختى گونه Saara asmussi. اعداد نمايش داده شده بر روى شاخهها نشاندهنده Posterior probabilities بالاى ها • در درخت

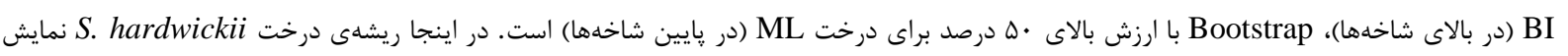

$$
\text { داده نشده است. }
$$

Fig. 2. Phylogenetic tree of Saara asmussi. Numbers on branches indicate values over 0.5 for Bayesian posterior probabilities (above branches), bootstrap support values over $50 \%$ for ML (below branches). In this tree, the outgroup S. hardwickii is not depicted.

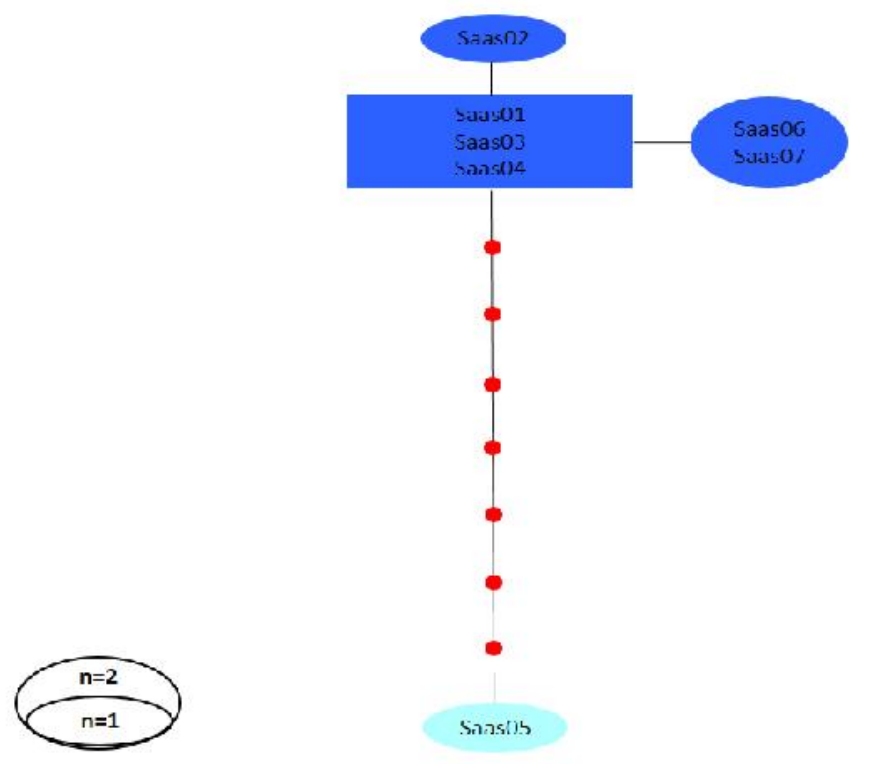

شكل r- شبكه آمارى پارسيمونى بر اساس زن ميتوكندريايى سيتوكروم b، ارتباط درون گونه Saara asmussi در ايران را نشان مى دهد. نقاط قرمز نشان

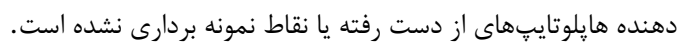

Fig. 3. Statistical parsimony network, based on mitochondrial cytochrome b, represents the relationship among haplotypes of Saara asmussi .Red dots represent step mutations. 


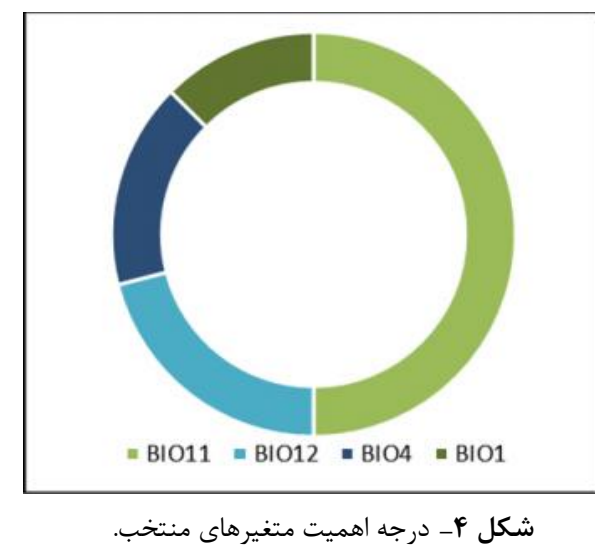

Fig. 4 .The importance of selected variables

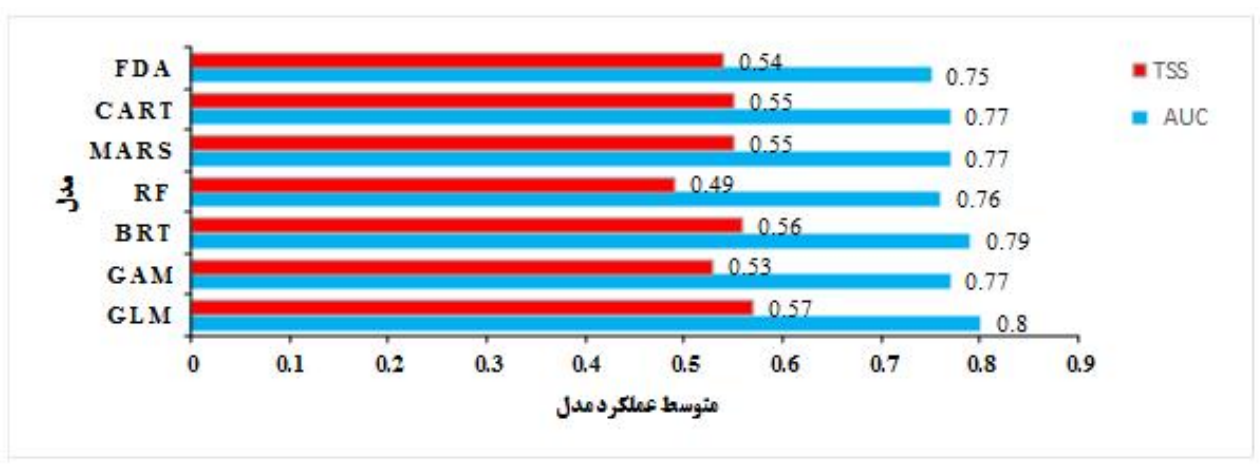

شكل ه- ارزيابى عملكرد مدلها.

Fig. 5. Assessing model performance.
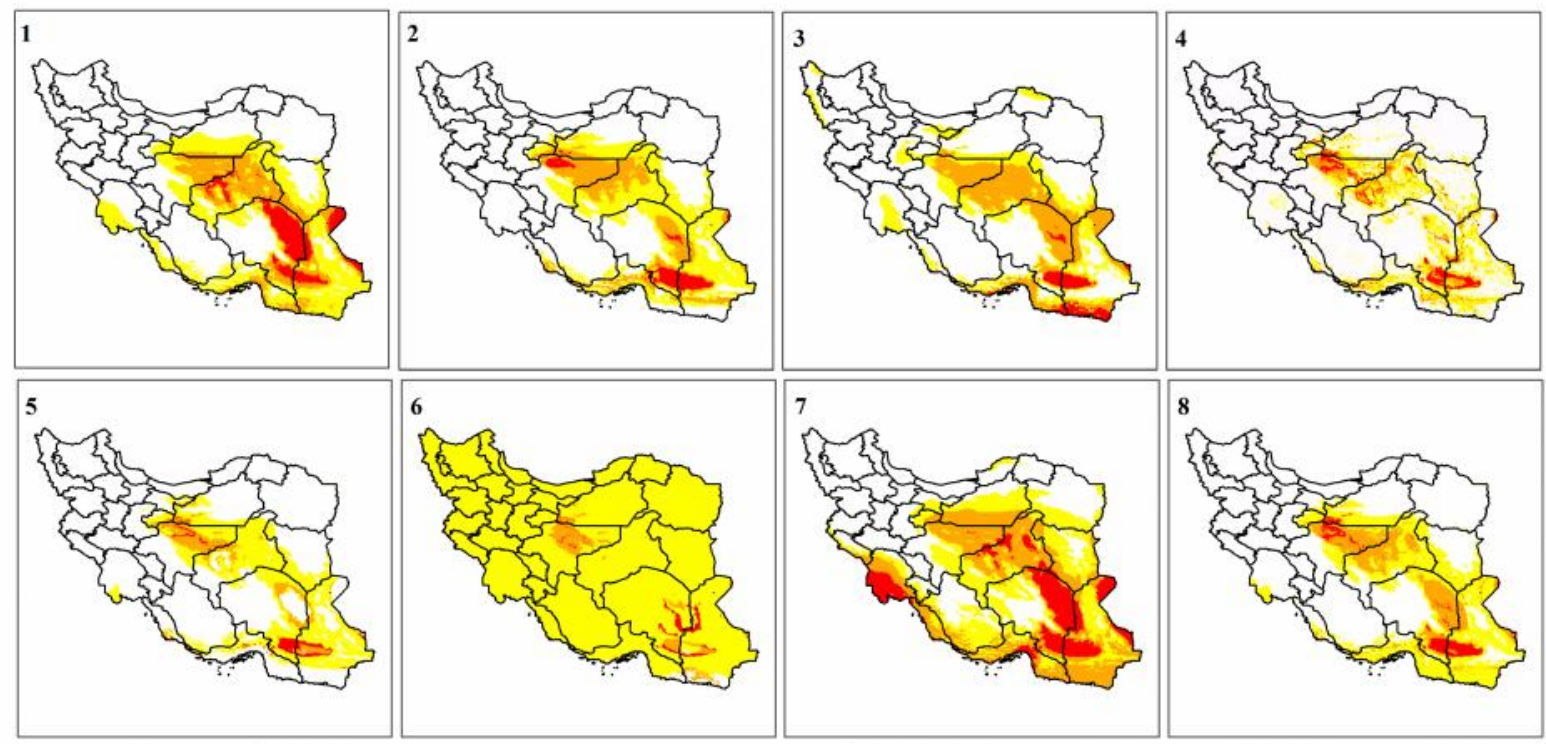

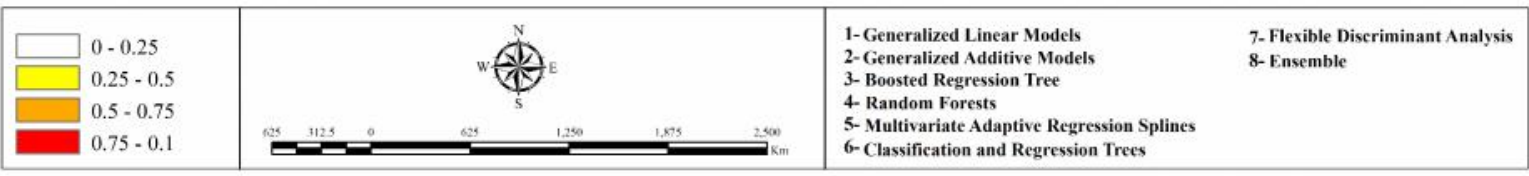

شكل צ- پِيشبينى توزيع Saara asmussi بر اساس شرايط اقليمى كنونى در ايران.

Fig. 6. Predicting Saara asmussi distribution based on current climatic conditions in Iran. 


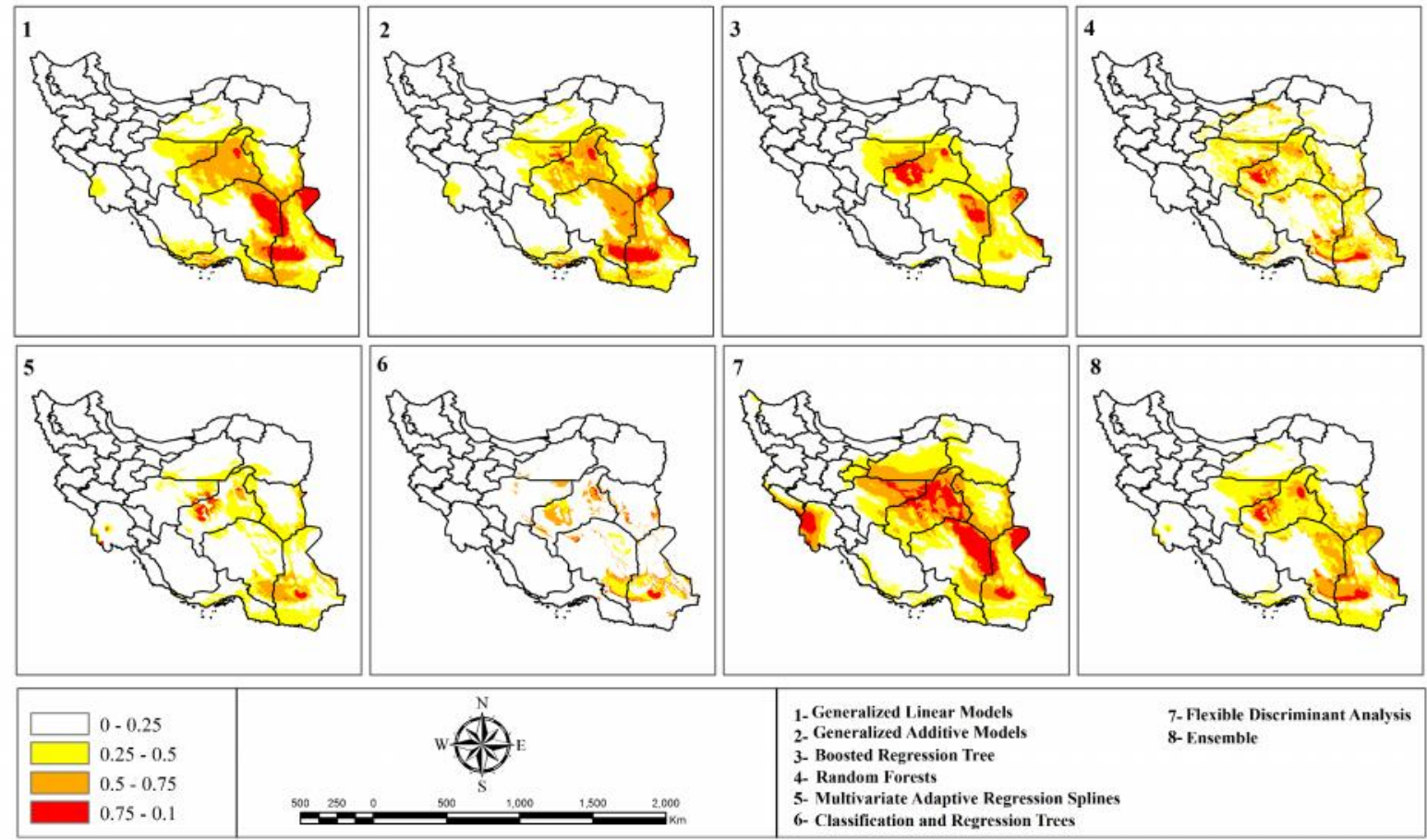

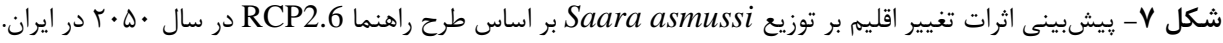

Fig. 7. Predicting climate change effects on the distribution of Saara asmussi based on RCP2.6 scenario in Iran by the year 2050 .

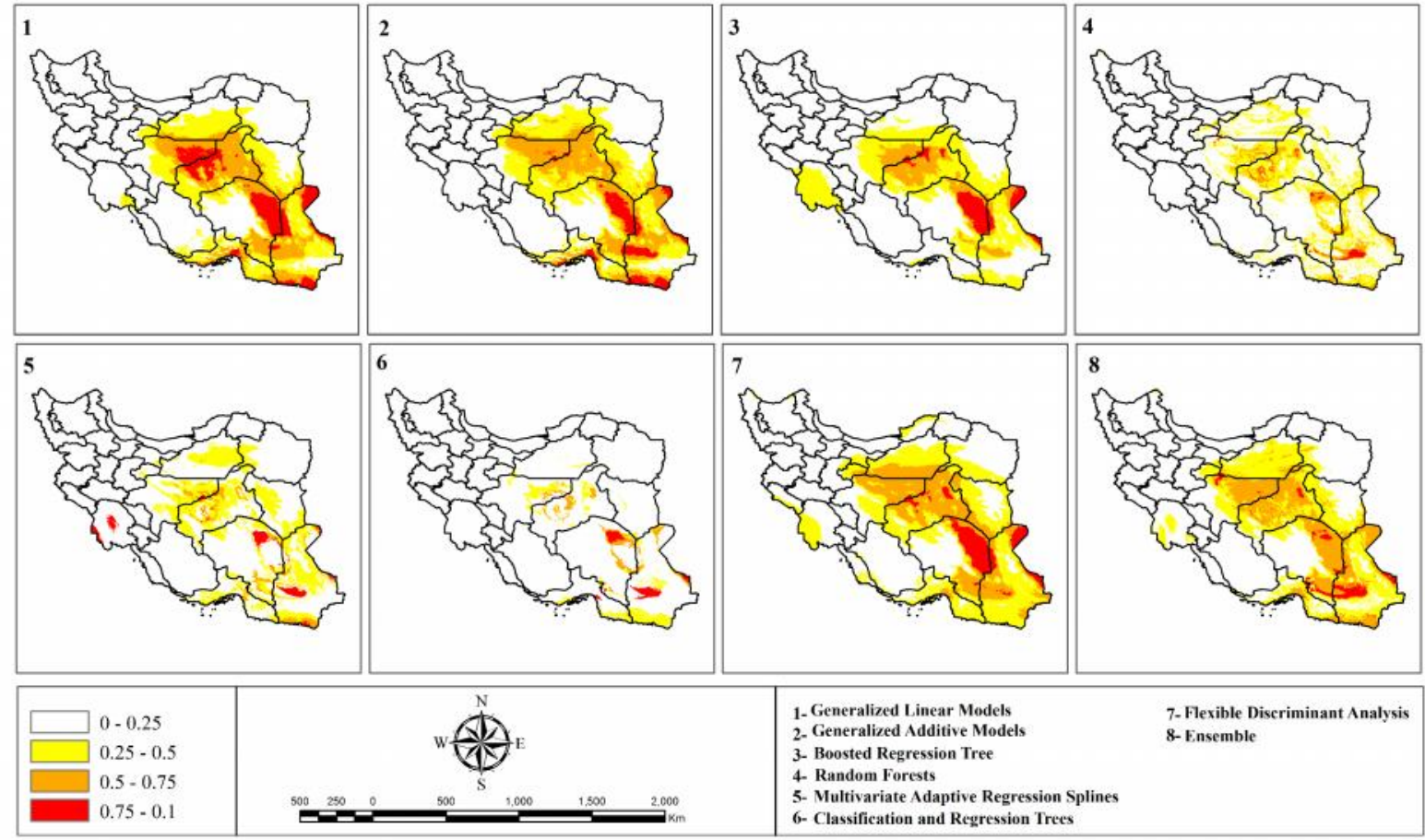

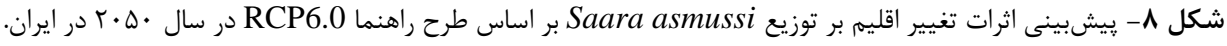

Fig. 8. Predicting climate change effects on the distribution of Saara asmussi based on RCP6.0 scenario in Iran by the year 2050 . 
مىرسد اين لكههاى كو جكى زيستًاهى پارامترهاى اقليمى مطلوب

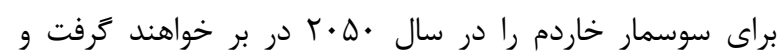

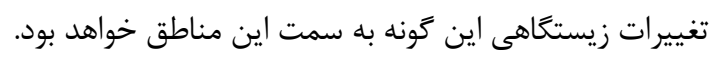

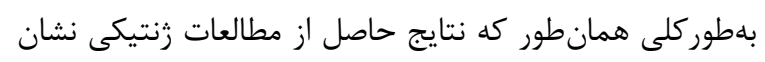

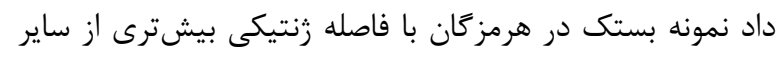

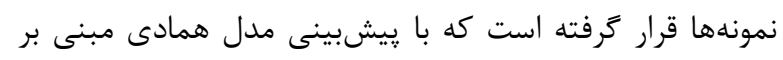

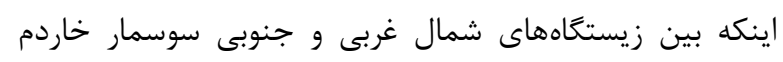

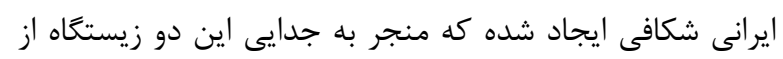

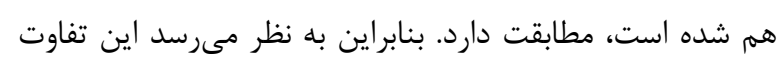

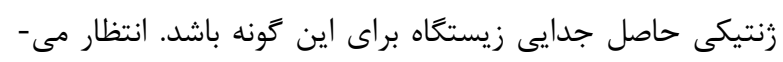

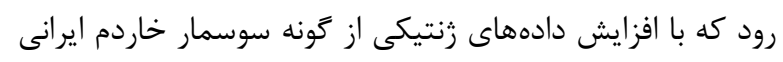

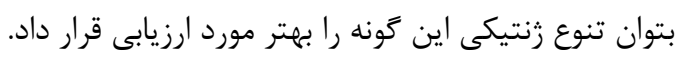

\section{نتيجه كيرى}

در اين مطالعه به بررسى وضعيت سوسمار خاردم ايرانى از

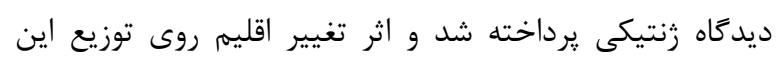

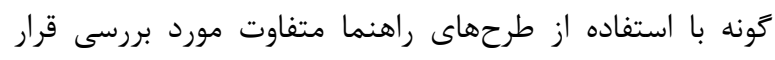

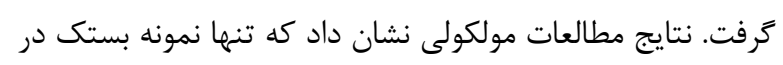

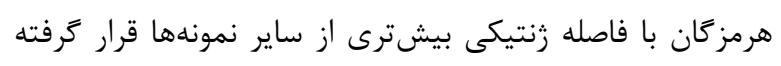

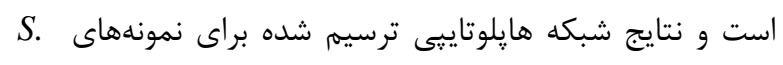

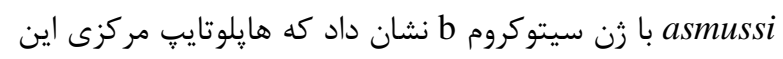

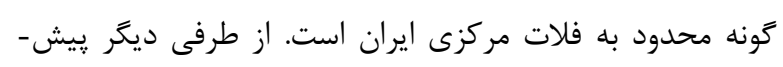

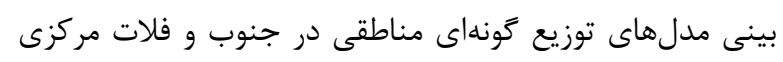

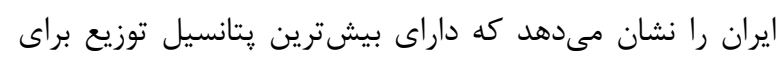

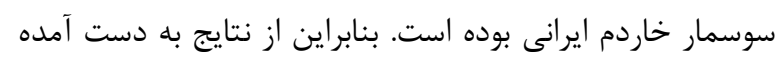

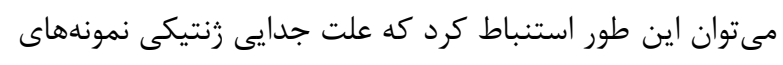

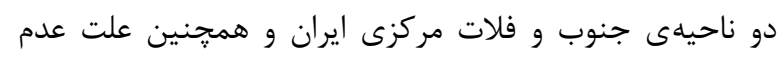

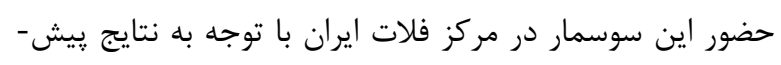

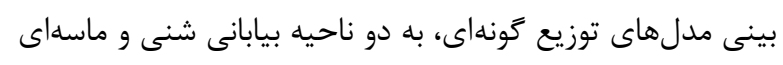

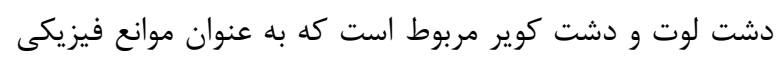

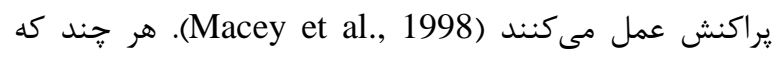

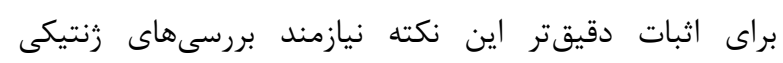
كستردهتر است.

\section{سواسگزارى}

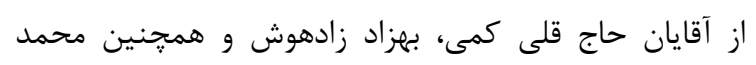

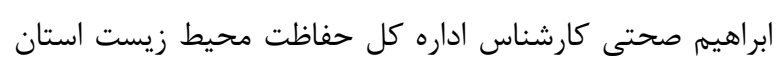

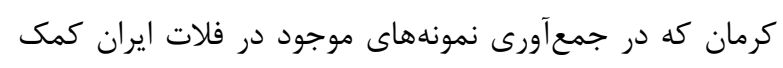

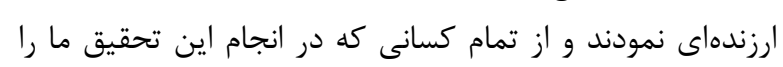
يارى رساندند، تشكر مى تردد.
فلات ايران جلوكيرى نمايد. بنابراين به نظر مىرسد با بهوجود

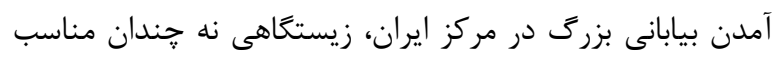

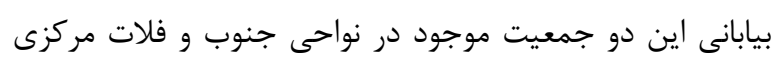

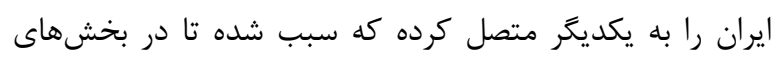

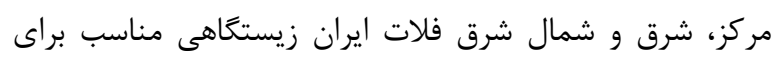

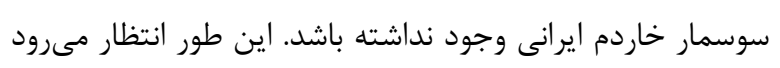

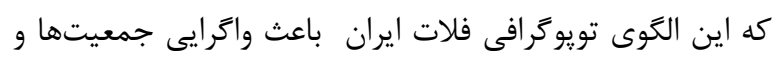
كونههايى شود كه در آن قرار كرفتنهاند (Macey et al., 1998)

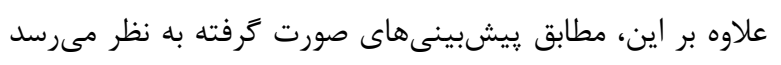

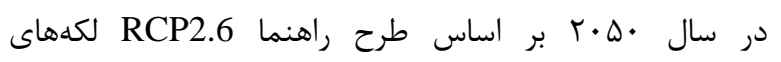

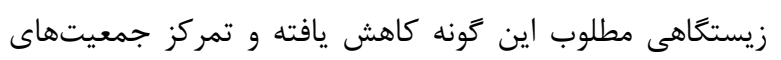
اين تونه در بخشهاى شرق و غرب استان سيستان و بلوجستان،

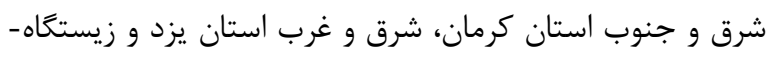

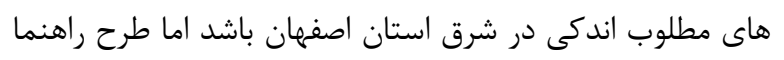

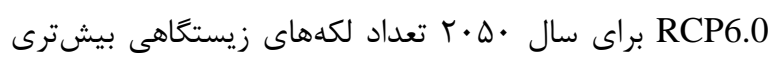

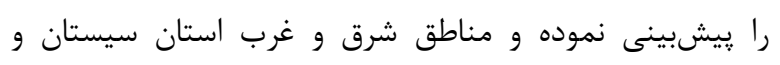

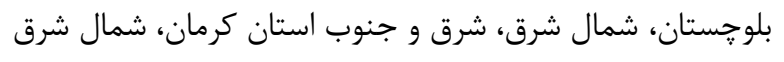

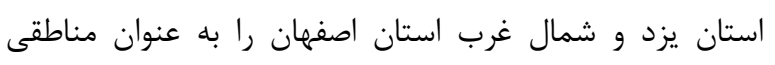

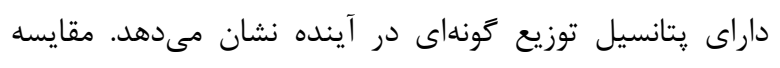

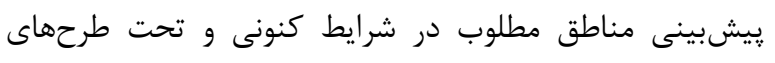

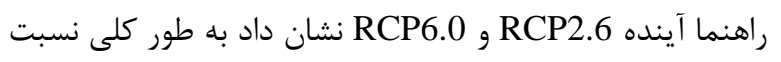

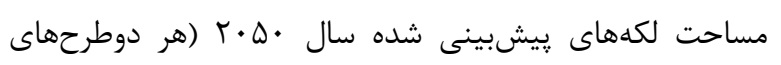

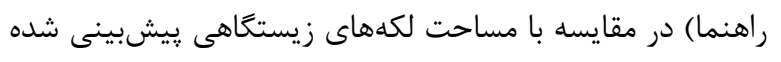

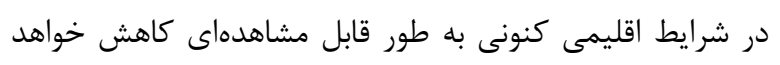

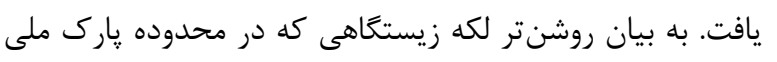

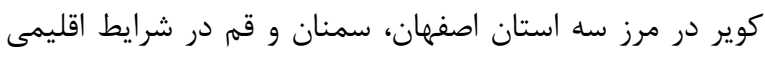

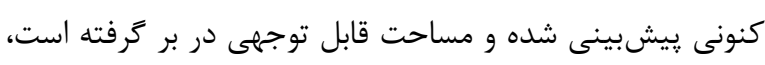

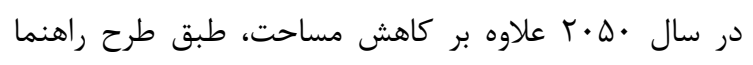

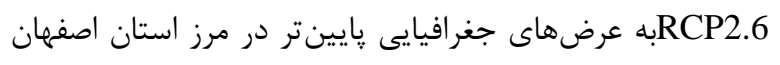
و يزد و طبق طرح راهنما RCP6.0 به شمال استان اصفهان

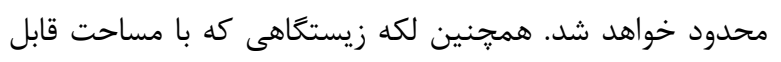

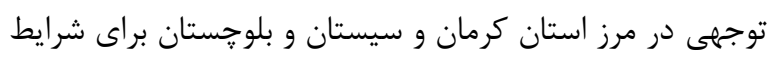

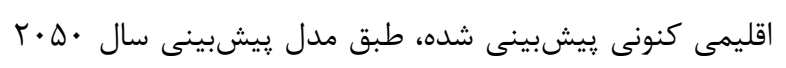

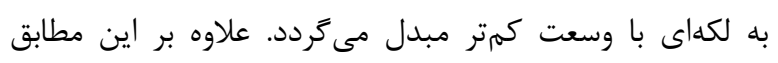

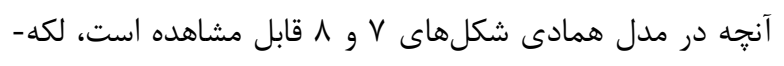

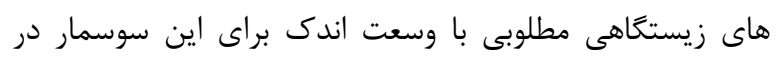

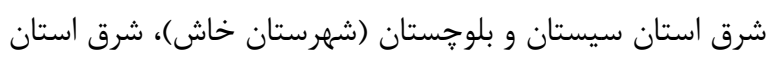

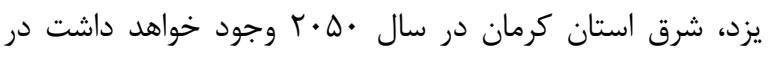

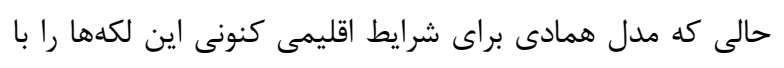

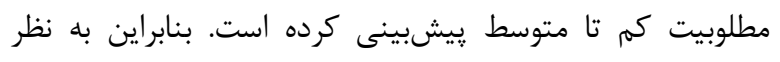




\section{REFERENCES}

Ahmadzadeh, F., Carretero, M.A., Rödder, D., Harris, D.J., Freitas, S.N., Perera, A. \& Böhme, W. 2013. Inferring the effects of past climate fluctuations on the distribution pattern of Iranolacerta (Reptilia, Lacertidae): Evidence from mitochondrial DNA and species distribution models. Zool. Anz. 252: 141-148.

Akbari, H., Jalalpour, M., Hojati, V. \& Golmohammadi, M.S. 2011. The study of reptiles and birds of Abbas Abad wildlife refuge in Naein, Isfahan province. J. Animal Biol. 3: 1-12.

Akbari, H., Varasteh Moradi, H., Baghestani, N. \& Rezaei, H.R. 2014. Food preferences and composition of Chinkara (Gazella bennettii shikarii) in spring season in Darreh Anjir wildlife refuge, Yazd, Iran. Arid Biom. 4: 1-9.

Allouche, O., Tsoar, A. \& Kadmon, R. 2006. Assessing the accuracy of species distribution models: prevalence, kappa and the true skill statistic (TSS). J. Appl. Ecol. 43: 1223-1232.

Amer, S.A.M. \& Kumazawa, Y. 2005. Mitochondrial DNA sequences of the Afro-Arabian spiny-tailed lizards (genus Uromastyx, family Agamidae): phylogenetic analyses and evolution of gene arrangements. Biol. J. Linn. Soc. 85: 247-260.

Ananjeva, N.B., Orlov, N.L., Khalikov, R.G., Darevsky, S.I., Ryabov, S.A. \& Barabanov, A.V. 2006. The reptiles of Northern Eurasia. Pensoft Ser. Faunist. 47 pp.

Anderson, S.C. 1974. Preliminary key to the turtles, lizards and amphisbaenians of Iran. Fielddiana Zool. 65: 27-44.

Anderson, S.C. 1999. The lizards of Iran. Society for the study of amphibians and reptiles (SSAR). Oxford, Ohio. pp: 1-442.

Araújo, M.B. \& New, M. 2007. Ensemble forecasting of species distributions. Trends Ecol. Evol. 22: 42-47.

Araújo, M.B., Whittaker, R.J., Ladle, R.J. \& Erhard, M. 2005. Reducing uncertainty in projections of extinction risk from climate change. Global Ecol. Biogeogr. 14: 529-538.

Armstrong, J.S. 2001. Combining forecasts. Principles of forecasting. Kluwer Academic Publishers, Springer. 30: 417-439.

Arnold, E.N. 1986. The hemipenis of lacertid lizards (Reptilia: Lacertidae): structure, variation and systematic implications. J. Nat. Hist. 20: 1221-1257.

Bellwood, D.R., Hoey, A.S. \& Choat, J.H. 2003. Limited functional redundancy in high diversity systems: resilience and ecosystem function on coral reefs. Ecol. Lett. 6: 281-285.

Blanford, W.T. 1876. Eastern Persia, an account of the journeys of the Persian boundary commission. Zoo. Geo. 2: 1870-1872.

Buckley, L.B. \& Roughgarden, J. 2006. Climate, competition, and the coexistence of island lizards. Funct. Ecol. 20: 315-322.

Clemen, R.T. 1989. Combining forecasts: A review and annotated bibliography. Int. J. Forecasting 5: 559-583.
Clement, M., Posada, D. \& Crandall, K. 2000. TCS: a computer program to estimate gene genealogies. Mol. Ecol. 9: 1657-1660.

Davies, T.J. \& Buckley L.B. 2011. Phylogenetic diversity as a window into the evolutionary and biogeographic histories of present-day richness gradients for mammals. Phil. Trans. R. Soc. B. 366: 2414-2425.

Ebrahimi, E. 2018. Determination of habitat hotspots for common mammals using species distribution models. Shahid Beheshti University. M.Sc. Thesis. 182 pp.

Elith, J., Graham, C.H., Anderson, R.P., Dudik, M., Ferrier, S., Guisan, A., Hijmans, R.J., Huettmann, F., Leathwick, J.R., Li, J., Lohmann, L.G., Loiselle, B.A., Man-ion, G., Moritz, C., Nakamura, M., Nakazawa, Y., Overton, J.M.M., Peterson, A.T., Phillips, S.J., Richardson, K., ScachettiPereira, R., Schapir, R.E., Soberón, J., Williams, S., Wisz, M.S. \& Zimmermann, N.E. 2006. Novel methods improve prediction of species' distributions from occurrence data. Ecography 29: 129-151.

Engstrom, T.N., Edwards, T., Osentoski, M.F. \& Myers, E.M. 2007. A compendium of PCR primers for mtDNA, microsatellite, and other nuclear loci for freshwater turtles and tortoises. Chelon. Res. Monogr. 4: 124-141.

Excoffier, L. \& Lischer, H.E.L. 2010. Arlequin suite ver 3.5: a new series of programs to perform population genetics analyses under Linux and Windows. Mol. Ecol. Resour. 10: 564-567.

Gaston, K.J. 2003. The Structure and Dynamics of Geographic Ranges. Oxford University Press, 99 pp.

Gaston, K.J. \& Spicer, J.I. 2004. Biodiversity: an introduction. Blackwell Science Ltd. 2nd Edition. 208 pp.

Global Climate Data, 2005. Published on the Internet https://www. worldclim.org [accessed March 2019]

Gray, J.E. 1845. Catalogue of the specimens of lizards in the collection of the British museum. British Museum (Natural History), London B.M. (N.H.), 289 pp.

Guisan, A. \& Thuiller, W. 2005. Predicting species distribution: offering more than simple habitat models. Ecol. Lett. 8: 993-1009.

Hijmans, R.J., Cameron, S.E., Parra, J.L., Jones, P.G. \& Jarvis, A. 2005. Very high resolution interpolated climate surfaces for global land areas. Int. J. Climatol. 25: 1965-1978.

Hoser Raymond, T. 2014. A long overdue taxonomic rearrangement of the Uromastycinae, Squamata, Sauria, Agamidae. Aust. J. Herpetol. 23: 54-64.

Huelsenbeck, J.P. \& Ronquist, F. 2001. MR-BAYES: Bayesian inference of phylogeny. Bioinformatics 17: 754-75.

Huntley, B., Green, R.E., Collingham, Y.C., Hill, J.K., Willis, S.G., Bartlein, P.J., Cramer, W., Hagemeijer, W.J. \& Thomas, C.J. 2004. The performance of models relating species geographical distributions to climate is independent of trophic level. Ecol. Lett. 7: 417-426. 
Jeschke, J.M. \& Strayer, D.L. 2008. Usefulness of bioclimatic models for studying climate change and invasive species. Ann. Ny. Acad. Sci. 1134: 1-24.

Joger, U. 1986. Phylogenetic analysis of Uromastyx lizards, based on albumin immunological distances. Studies in Herpetologie, SEH Prague, Bonn, Germany, pp: 187-191.

Kaliontzopoulou, A., Brito, J.C., Carretero, M.A., Larbes, S. \& Harris, D.J. 2008. Modelling the partially unknown distribution of wall lizards (Podarcis) in North Africa: ecological affinities, potential areas of occurrence, and methodological constraints. Can. J. Zool. 86: 992-1001.

Khan, M.S.H. 2002. Key and checklist to the lizards of Pakistan, (Reptilia, Squamata, Sauria). Herpetozoa. 15: 99-119.

Knapp, A. 2004. An assessment of the international trade in spiny-tailed lizards Uromastyx with a focus on the role of the European Union. Technical report to the European Commission, CITES Doc. AC. Inf. 13: 1-31.

Macey, J.R., Schulte, J.A., Ananjeva, N.B., Larson, A., Rastegar-Pouyani, N., Shammakov, S.M. \& Papenfuss, T.J. 1998. Phylogenetic relationships among Agamid lizards of the Laudakia caucasia species group: Testing hypotheses of biogeographic fragmentation and an area cladogram for the Iranian plateau. Mol. Phylogenet. Evol. 10: 118-131.

Manel, S., Williams, H.C. \& Ormerod, S.J. 2001. Evaluating presence-absence models in ecology: the need to account for prevalence. J. Appl. Ecol. 38: 921-931.

Mertens, R. 1956. Amphibien und reptilien aus dem SOIran. Jahreshefte des Vereins für vaterländische Naturkunde in Württemberg 111: 90-97.

Meynard, C.N., Devictor, V., Mouillot, D., Thuiller, W., Jiguet, F. \& Mouquet, N. 2011. Beyond taxonomic diversity patterns: how do $\alpha, \beta$ and $\gamma$ components of bird functional and phylogenetic diversity respond to environmental gradients across France? Global Ecol. Biogeogr. 20: 893-903.

Miller, J. 2010. Species distribution modeling. Geography Compass 4: 490-509.

Moody, S.M. 1987. A preliminary cladistic study of the lizard genus Uromatyx (Agamidae, sensu lato) with a checklist and diagnostic key to the species. Proc. Fourthord Gen Meet Soc. Eur. Herpetol. 1: 285-288.

Mouquet, N., Devictor, V., Meynard, C.N., Munoz, F., Bersier, L.F., Chave, J. \& Hardy, O.J. 2012. Ecophylogenetics: advances and perspectives. Biol. Rev. 87: 769-785.

Mutia, T.M. 2009. Biodiversity conservation. Short course IV on exploration for geothermal resources, organized by U.N.U-G.T.P., KenGen and G.D.C., at Lake Naivasha, Kenya 1-22.

Naimi, B. \& Araújo, M.B. 2016. sdm: a reproducible and extensible $\mathrm{R}$ platform for species distribution modelling. Ecography 39: 368-375.

Palumbi, S., Martin, A., Romano, S., McMillan, W., Stick, L. \& Grabowski, G. 1991. A simple fool's guide to PCR. Honolulu, HI: University of Hawaii Press, 46 pp.
Parmesan, C., Gaines, S., Gonzalez, L., Kaufman, D.M., Kingsolver, J., Townsend Peterson, A. \& Sagarin, R. 2005. Empirical perspectives on species borders: from traditional biogeography to global change. Oikos 108: 58-75.

Peterson, A.T. \& Vieglais, D.A. 2001. Predicting species invasions using ecological niche modeling: new approaches from bioinformatics attack a pressing problem. Bioscience 51: 363-371.

Pincheira-Donoso, D., Bauer, A.M., Meiri, S. \& Uetz, P. 2013. Global taxonomic diversity of living reptiles. PLoS One 8: e59741.

Porro, L.B., Ross, C.F., Iriarte, D.J., O'Reilly J.C., Evans, S.E. \& Fagan, M.J. 2014. In vivo cranial bone strain and bite force in the agamid lizard Uromastyx geyri. J. Exp. Biol. 217: 1983-1992.

Posada, D. 2008. jModelTest phylogenetic model averaging. Mol. Biol. Evol. 25: 1253-1256.

Rahimian, H., Shafiei, S., Rastegar-Pouyani, N. \& Rastegar-Pouyani, E. 2015. Phylogenetic relationships of the gray-toad agama, Phrynocephalus scutellatus (Olivier, 1807), species complex from Iran. Zootaxa. 3990: 369-380.

Rastegar Pouyani, E., Rastegr Pouyani, N., Kazemi Noureini, S., Joger, U. \& Wink, M. 2010. Molecular phylogeny of the Eremias persica complex of the Iranian plateau (Reptilia: Lacertidae), based on mtDNA sequences. Zool. J. Linn. Soc. Lond. 158: 641-660.

Sambrook, J. \& Russell, D.W. 2006. SDSpolyacrylamide gel electrophoresis of protein. Cold spring harbor laboratory press (CSHLP). 2006: pdbprot 4540 .

Sgro, C.M., Lowe, A.J. \& Hoffmann, A.A. 2011. Building evolutionary resilience for conserving biodiversity under climate change. Evol. Appl. 4: 326-337.

Stamatakis, A. 2006. RAxML-VI-HPC: maximum likelihoodbased phylogenetic analyses with thousands of taxa and mixed models. Bioinformatics 22: 26882690.

Szczerbak, N.N. 1974. The palearctic deserts lizards. Akadeimya Nauk Ukrienskoi SSR Institut Zoologii. Kiev: Naokova Dumka.

Szczerbak, N.N. 2003. Guides to the reptiles of the Eastern Palaearctic. Krieger Pub. CO. Malabar, 260 pp.

Tamar, K., Metallinou1, M., Wilms, T., Schmitz. A., Crochet, P.A., Geniez, P. \& Carranza1, S. 2017. Evolutionary history of spiny-tailed lizards (Agamidae: Uromastyx) from the Saharo-Arabian region. Zool. Scr. 47: 159-173.

Tamura, K., Peterson, D., Stecher, G., Filip, A. \& Kumar, S. 2013. MEGA6: molecular evolutionary genetics analysis version 6.0. Mol. Biol. Evol. 30: 2725.

The Global Biodiversity Information Facility. 2018. Published on the Internet https://www.gbif.org [accessed November 2018] 
Trisurat, Y., Shrestha, R.P.\& Alkemade, R. 2011. Land use, climate change and biodiversity modeling: perspectives and applications. Information Science Reference, $512 \mathrm{pp}$.

Vazquez, D.P. \& Gittleman, J.I. 1998. Biodiversity conservation: Does phylogeny matter? Curr. Biol. 8: 379-381.

Wilms, T. \& Böhme, W. 2007. Review of the taxonomy of the spiny-tailed lizards of Arabia (Reptilia, Agamidae, Leiolepidinae, Uromastyx). Fauna Arabia 23: 435-468.
Wilms, T. \& Schmitz, A. 2007. A new polytypic species of the genus Uromastyx Merrem 1820 (Reptilia, Squamata, Agamidae, Leiolepidinae) in southwestern Arabia. Zootaxa 1394: 1-23.

Wilms, T., Bohmes, W., Wagner, P., Lutzmann, N. \& Schmitz, A. 2009. On the phylogeny and taxonomy of the genus Uromastyx Merrem, 1820 (Reptilia, Squamata, Agamidae, Uromastycinae) resurrection of the genus Saara Gray, 1845. Bonn. Zool. Beitr. 56: 55-99.

How to cite this article:

Ghaedi, Z., Saberi-Pirooz, R., Ebrahimi, E., Badri. S. \& Ahmadzadeh, F. 2020. Genetic diversity within the Iranian spiny-tailed lizard and predicting species distribution in climate change conditions. Nova Biologica Reperta 7: $192-205$. (In Persian).

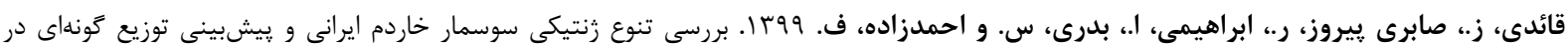

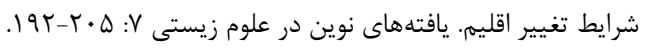

